\title{
BANDWIDTH ENHANCEMENT OF 4GHZ RMSA FOR WIRELESS COMMUNICATION APPLICATION
}

\author{
R.Satyanarayana ${ }^{1}$, Shankaraiah ${ }^{2}$ \\ ${ }^{I}$ Research Scholar - Electronics, JSS Research Foundation, SJCE, Department of Electronics and Communication \\ Engineering, Mysore, (Karnataka) India \\ ${ }^{2}$ Professor, JSS Research Foundation, SJCE, Department of Electronics and Communication Engineering, Mysore
}

(Karnataka) India

\begin{abstract}
The development of wireless communication technologies widely using microstrip antenna, has attracted much attention in recent years. In wireless communication, Microstrip antenna is important device for communication above $1 \mathrm{GHz}$. It is used in mobile communication, aircraft and satellite communication applications. Microstrip antenna has advantage of Low Profile, easy to fabricate, easy to feed, incorporate with other array elements and other microstrip elements. In this paper a rectangular microstrip antenna ( RMSA) is designed for $4 \mathrm{GHz}$ resonating frequency. The Substrate height is doubled so that effective dielectric constant is changed. As a result of this, it enhances the bandwidth of RMSA.
\end{abstract}

RMSA is simulated using HFSS, using epoxy substrate of relative permitivity Er=4.4 and thickness of 1.6mm and 3.2. Results describes that bandwidth enhancement can be obtained by increasing the height of substrate.

Keywords: HFSS, Wireless communication

\section{INTRODUCTION}

Antenna is a device or piece of conductor which converts electrical signal into electromagnetic waves \& vice versa. There are different types of Antennas working at different frequencies. The microstrip antenna was invented by Bob Munson in 1972. Microstrip antenna is very simple to fabricate \& has main applications in frequencies above $1 \mathrm{GHz}$. [1] Microstrip antenna contains two metal layers on both sides of a dielectric material. The bottom layer patch having larger area is called ground plane and top metal layer of suitable shape is called a patch. [2] It is also called as patch antenna and Patch can be of any shapes. Most commonly used shapes are Rectangular \& circular.

The Microstrip Antenna works on the cavity resonating principle. The patch acts approximately as cavity. The top and bottom patch acts as a short circuited walls and open circuited at the sides. In the cavity only certain modes are allowed to exist at different resonant frequencies. If the antenna is excited at resonant frequency, a strong field is set up, inside the cavity and strong current in the bottom patch plane surface. This produces a significant radiation and works as a good antenna.

Microstrip Antenna is low profile, compact, small in size, less weight. It is Easy to fabricate using Photo lithography and etching techniques. It is easy to feed simple methods such as coaxial cable, microstrip line etc. Microstrip Antenna is easy to use in array or include with other microstrip circuit elements. The
Major characteristics of Microstrip antenna are also makes it suitable for application in wireless mobile communication, aircraft and satellite communication. The radiation pattern is somewhat hemispherical and moderate directivity.

The disadvantages of Microstrip antenna are low bandwidth. The bandwidth can be increased by a number of techniques. Lot of research is going on this area and many research groups are working towards increasing the bandwidth of Microstrip Antenna. [3] The bandwidth can be varied by changing different substrate materials , having various values of relative permittivity Er [5] The bandwidth can also varied by changing values of Design dimensions[6]. An egg shaped slot antenna is designed to increase the impedance Bandwidth [7] by varying Design parameters. The egg shaped curve is introduced by introducing egg shaped parameter in the standard elliptic curve equation. To validate the theoretical value, egg curved slot antenna was designed, which gives better bandwidth (164\%) for S11 above $-10 \mathrm{~dB}$ and also gives improvement in gain. Antenna miniaturization and bandwidth enhancement is achieved by reactive impedance surface (RIS) . The reactive impedance substance as a substrate [8] for a printed antenna provides both miniaturization., significant bandwidth improvement. It is demonstrated that RIS can perform superior to PMC , when used as a substrate of the antenna. The RIS is designed using two dimensional periodic pointed metallic 
patches on a baked high dielectric material. It provides a better performance antenna than designed with PEC \& PMC dielectric .It gives Bandwidth, gain and radiation efficiency better than that of PEC and PMC substrate materials . Bandwidth of a wide slot antenna is also improved by using parasitic patch [9]. Another disadvantage of microstrip is efficiency is less than other antennas. The efficiency is limited by conductor and dielectric losses.[4] There is a scope for improvement in this area also.

In this paper, Rectangular microstrip Antenna has been designed at 4GHZ. The Antenna has been designed with substrate height of $1.6 \mathrm{~mm}$ and then increased the height of $3.2 \mathrm{~mm}$ to increase the Bandwidth. The B.W of $1.6 \mathrm{~mm}$ is compared with B.W of increased height of substrate. The antenna has been designed with substrate height of $1.6 \mathrm{~mm}$ with epoxy dielectric having $E r=4.4$. The Paper is organized as follows. Design method and analysis is explained in section II. Simulation results and comparison of results are explained in section III. Conclusion \& Future work remarks is given in section IV. Acknowledgment is given section $\mathrm{V}$.

\section{DESIGN OF PROPOSED RMSA 4GHZ ANTENNA}

The microstrip antenna is constructed on a very thin dielectric substrate using different etching techniques. In general, dual copper coated Teflon fiberglass is most commonly used so that the microstrip can be easily curved to the shape of mounting surface. For patch mostly conducting materials such as copper or gold is used. In almost all the antennas the fed lines are photo etched on the substrate along the patch.

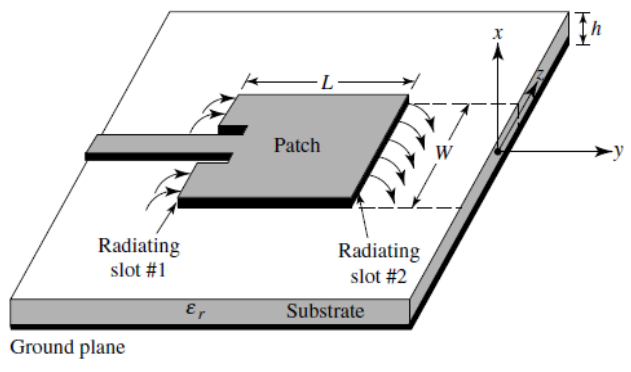

(a) Microstrip antenna

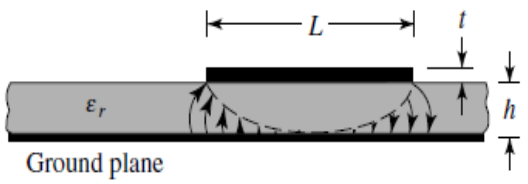

(b) Side view

In Microstrip Antenna the Length, Width \& height are Design parameters. Length is the resonating parameter. The width is designed such that it is larger than $\mathrm{L}$. Generally $\mathrm{W}=1.5 \mathrm{~L}$ is selected in typical cases. Length, Width and feeder dimensions are Design parameters that are calculated as explained below.

\section{Calculating Length \& Width of Antenna}

A Rectangular microstrip patch antenna for resonating frequency of $4 \mathrm{GHz}$ with FR 4 material of thickness of $1.6 \mathrm{~mm}$ is designed by steps of following algorithm. The length and width calculations are given below.

The width is calculated using formula

$$
W=\frac{C}{2 f r \sqrt{ } 2}\left(\frac{1}{E r+1}\right)
$$

Where $\mathrm{C}$ is speed of light

Fr is resonating frequency

Er is the dielectric constant of FR 4

The effective dielectric dielectric constant is calculated

$$
\text { Eeff }=\left(\frac{E r+1}{2}+\frac{E r-1}{2}\right) * 1 / \sqrt{ }\left(1+\frac{\overline{12 h}}{w}\right)
$$

The extended length is calculated by

$\boldsymbol{\Delta} \mathbf{\Lambda} \mathrm{L}=0.412 * \mathrm{~h}[($ Eeff +0.3$)(\mathrm{W} / \mathrm{h}+0.264) /$

$($ Eeff +0.3$)(\mathrm{W} / \mathrm{h}+0.6)]$

The Length $\mathrm{L}$ is calculated by

$L=\left(\frac{E r}{2 f r \sqrt{E R}}\right)-2 \mathbf{\Delta} \mathrm{L}$

After calculation the length is found to be $16.6 \mathrm{~mm}$ and width is $22.6 \mathrm{~mm}$.

\subsection{Calculate Feed Point \& Feeder Dimensions.}

The feeder is located at distance and feeder dimensions are calculated by using formulas given in [4]

\section{SIMULATION AND TESTING}

The Rectangular Microstrip is designed and simulated using HFSS using Epoxy substrate $\mathrm{Er}=4.4$ and first thickness of $1.6 \mathrm{~mm}$ and it is found the antenna is resonating with narrow bandwidth of $85.5 \mathrm{MHz}$. Then we increased the thickness to $3.2 \mathrm{~mm}$, the dimensions are readjusted. The antenna is simulated and bandwidth found be improved to $170.8 \mathrm{MHz}$. 


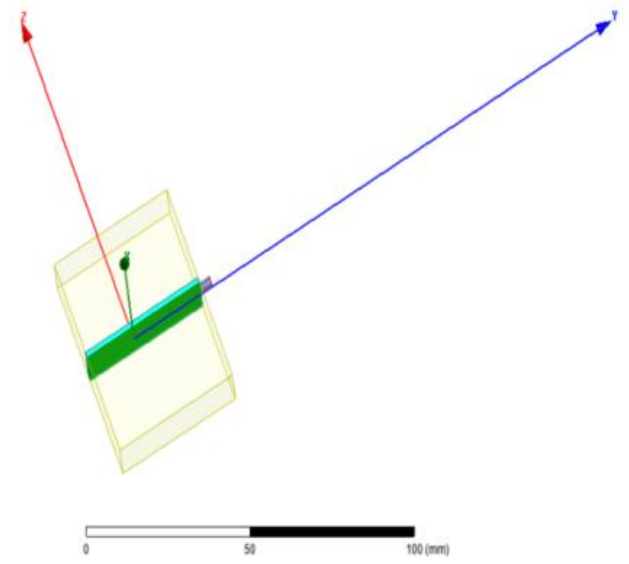

Fig 1 : RMSA Ground plane view

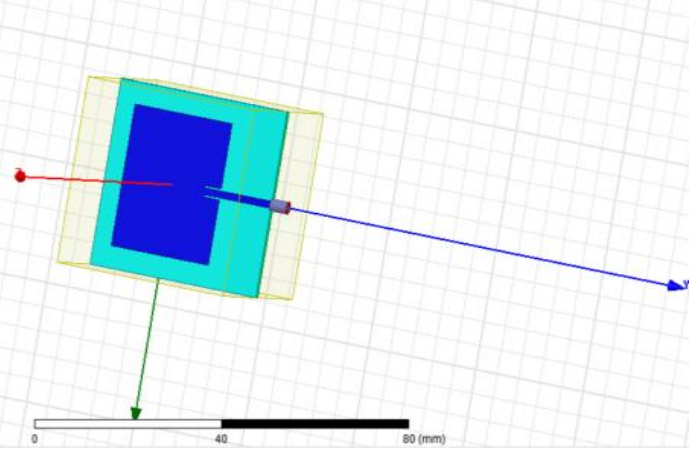

Fig 2 : RMSA Patch area view

The RMSA 4GHz is simulated using HFSS with $1.6 \mathrm{~mm}$ substrate thickness and then modified to $3.2 \mathrm{~mm}$. Figure 1 shows the Ground plane view of RMSA and Figure 2 shows Patch area of simulated RMSA. Table 1 gives the dimension of RMSA 4 GHZ $1.6 \mathrm{~mm}$ dielectric substrate thickness.

Table 1 : RMSA 4GHz dimensions

\begin{tabular}{|c|c|c|}
\hline Sl. No. & Description & Dimension $\mathbf{~ m m}$ \\
\hline 1 & Width & 22.6 \\
\hline 2 & Length & 16.6 \\
\hline 3 & Distance of feed point & 5.0058 \\
\hline
\end{tabular}

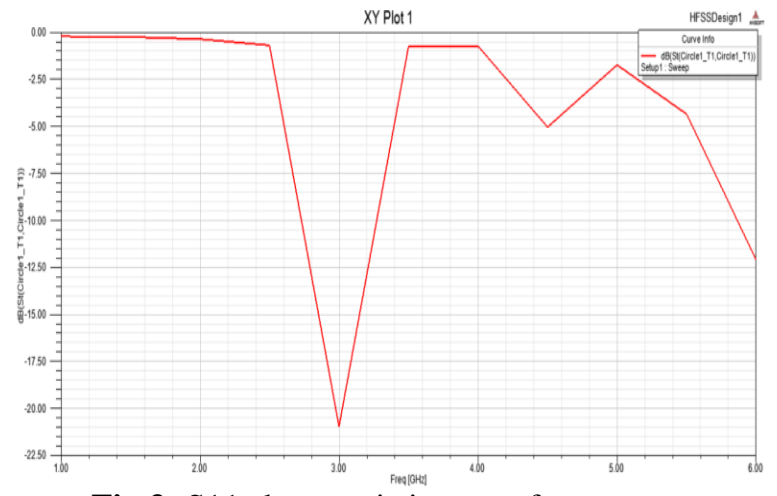

Fig 3: S11 characteristics w.r.t frequency .

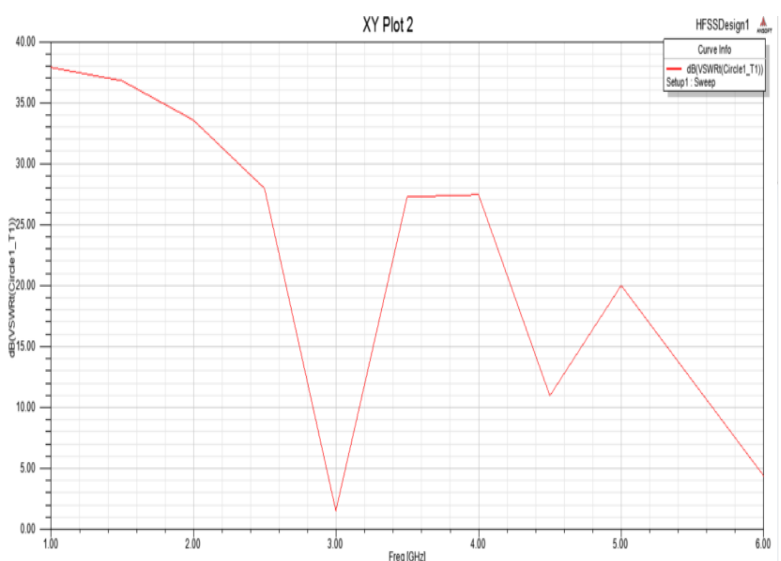

Fig 4: VSWR characteristics w.r.t frequency

Reflection Coefficient (S11) and VSWR are of RMSA shown in Figure 3 \& VSWR in Figure 4. Reflection coefficient S11 characteristics of w.r.t frequency. Maximum value of $-21 \mathrm{~dB}$ is achieved. It provides a very good isolation. Figure 4 gives VSWR characteristics w.r.t frequency and a value of 30 and minimum of 1 is obtained. Which meets the requirement.

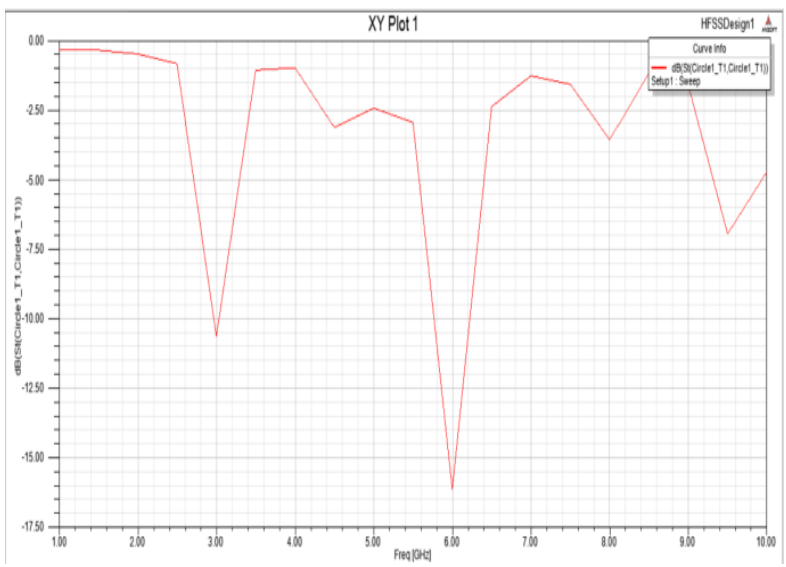

Fig 5: Modified RMSA S11 Characteristics w.r.t frequency

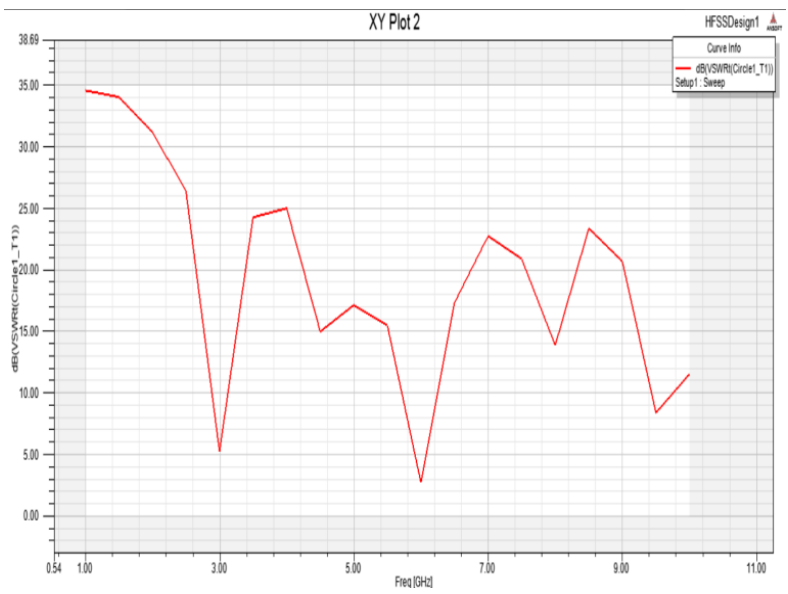

Fig 6: Modified RMSA VSWR characteristics w.r.t frequency . 
Figure 5 gives S11 characteristics of modified antenna and a maximum $-16 \mathrm{~dB}$, which provides good isolation and meets the requirements. Figure 6 gives modified antenna VSWR characteristics w.r.t frequency. A maximum of 35 and minimum of 2 is meeting the requirements of wireless communication application.

Table 2: RMSA 4GHz comparison of parameters

\begin{tabular}{|c|c|c|c|}
\hline Sl. No. & $\begin{array}{c}\text { Parameter } \\
\text { description }\end{array}$ & $\begin{array}{c}\text { RMSA 4 } \\
\text { GHZ } \\
\text { Antenna }\end{array}$ & $\begin{array}{c}\text { RMSA 4 } \\
\text { GHZ } \\
\text { modified } \\
\text { Antenna }\end{array}$ \\
\hline 1 & $\begin{array}{c}\text { S11 } \\
\text { maximum }\end{array}$ & -21 dB & -16 dB \\
\hline 2 & $\begin{array}{c}\text { VSWR } \\
\text { maximum }\end{array}$ & 30 & 35 \\
\hline 3 & $\begin{array}{c}\text { VSWR } \\
\text { minimum }\end{array}$ & 1 & 2 \\
\hline
\end{tabular}

The Table 2 gives the comparison of S11 and VSWR of RMSA 4 GHZ and modified RMSA. The S11> $-10 \mathrm{~dB}$ and it provides a good isolation.
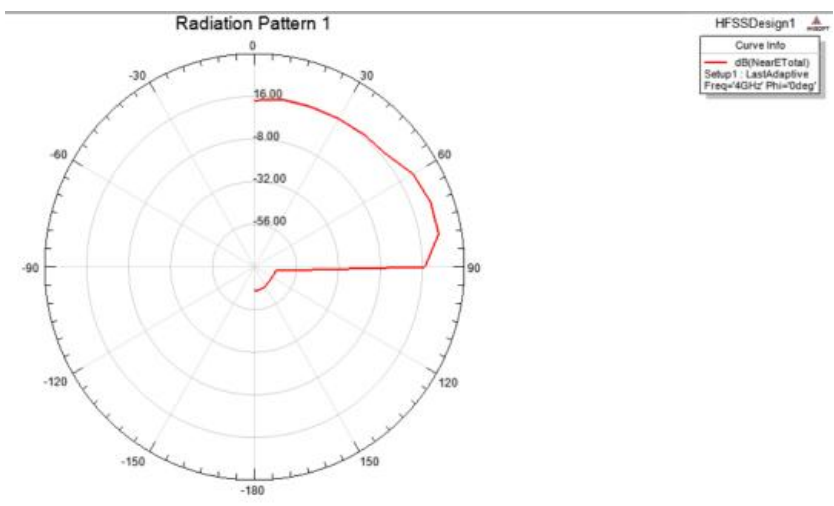

Fig 7: Radiation pattern 1 of RMSA
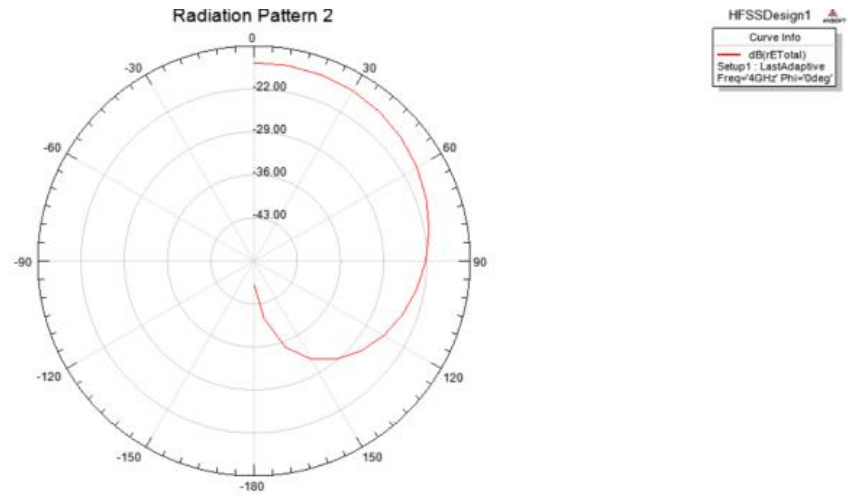

Fig 8: Radiation pattern 2 of RMSA

The Radiation pattern are also simulated for RMSA 4GHz. Figure 7 and 8 shows the radiation pattern 1 \& Radiation pattern 2 of RMSA $4 \mathrm{GHz}$. From simulation pattern, it is found to be meeting the application requirement.

\section{CONCLUSION \& FUTURE WORK}

Rectangular microstrip antenna is designed and bandwidth enhancement of $85.3 \mathrm{MHz}$ ( from $85.5 \mathrm{MHz}$ to $170.8 \mathrm{MHz}$ ) is achieved by increasing height of dielectric substrate .

Further improvement of bandwidth can be carried oout by incorporating other techniques like DGS, U-slot. Ssimulation results can be further improved and ccompared with fabricated antenna measured results.

\section{ACKNOWLEDGMENT}

The author is very much thank full to Dr. Shanmukha Swami Prof \& HOD of Electronics \& communication Engg., S.J.C.E Mysore for his encouragement \& support and for providing all facilities.

\section{REFERENCES}

[1] Jibendu Sekhar Roy, Milind Thomas, "Compact and BroadbandMicrostrip Antennas for Next Generation High-SpeedWireless Communication Using HIPERLAN/2", International Journal of Microwave Science and Technology Volume 2007, Article ID 75320, 4 pages doi:10.1155/2007/75320.

[2] J J. S. Roy, N. Chattoraj, and N. Swain, "Shortcircuited microstrip antennas for multiband wireless communications," Microwave and Optical Technology Letters, vol. 48, no. 12, pp.2372-2375, 2006.

[3] D. Guha, "Resonant frequency of circular microstrip antennas with and without airgaps," IEEE Trans. Antennas Propagation, vol. 49, pp. 55-59, Jan. 2001.

[4] C. A. Balanis, "Antenna Theory Analysis and Design", John Wiley and Sons. Inc.

[5] Gullu Kiziltas , Pschoudokis and Norboru kikruchi "Topology Design optimization of Dielectric substrates for Bandwidth improvement of a patch Antenna. " IEEE Trans. On Antennas and Propagation Vol. 51, No 10 October 2003

[6] Halappa R. Gajera " Edge Truncated square microstrip Patch Antenna [ET-CSMPA] for wireless application." IEEE 978-1-4577-1457-3/11 , 2011

[7] Sudhanshu verma and Preetham Kumar "Printed Egg curved slot Antenna for Wideband Application." Progress in Electromagnetics B , Vol. 58 , 111-121 2014

[8] Hassein Mosallaei and Kamal sarabandi , “ Antenna Miniaturization and Bandwidth Enhancement using a Reactive impedance substrate. “ IEEE Trans. On Antennas and Propagation Vol. 52, No 09 September 2004

[9] Y. Sung. “ Bandwidth Enhancement of Microstrip LineFed printed wide slot Antenna with parasitic centre patch "IEEE Trans. On Antennas and Propagation Vol. 60 , No 4 April 2012 